\title{
IoT based Energy Saving Strategies for Student Hall at University of Chittagong, Bangladesh
}

\author{
lqbal Ahmed \\ Dept. of Computer Science \& Engineering \\ University of Chittagong \\ Chittagong-4331, Bangladesh
}

\author{
Md. Yeasir Arafat \\ Dept. of Computer Science \& Engineering \\ University of Chittagong \\ Chittagong-4331, Bangladesh
}

\begin{abstract}
Controlling household electric devices automatically and remotely is of great beneficial and energy saving in modern life. We can design a small IoT based setup that can do a lot of work for us to make life easier. This system can be used in home, office, industries and all other places. Even we can use the system in the case of street light. Disabled people can be greatly benefited by using the system. To implement the system, we need a micro-controller with WIFI module to connect to the Internet. A front-end mobile application and a backend server will work together to make the project work smartly and intelligently. A student residence named 'Shaheed Abdur Rab Hall' in Chittagong University, Bangladesh has been considered for the implementation of the proposed system. It has been found that $24 \%$ energy can be saved using the proposed system and it found very much cost effective.
\end{abstract}

\section{General Terms}

Energy Saving using IoT, Cost- efficiency, Home-automation.

\section{Keywords}

IoT, Home-automation, nodeMCU, WIFI module, Cloud Server, Remote Controlling, Energy Saving, Energy Costing

\section{INTRODUCTION}

In this paper, an IoT based home automation and remote controlling system has been proposed and the analysis on energy usage of the proposed system and regular system has been performed. Here, regular system refers to the system we have been using for a long time that is not smart and connected to the Internet. Many electric components can be connected together with the help of IoT technology. Then they can be programmed to run them automatically and smartly with the help of a smartphone and a cloud server. Life can be easier and energy can be saved with the help of proposed system. Those, who cannot move, will be benefited using the system. Automatic alarm system can also be implemented using the system.

Home automation system has been proposed and implemented vastly in the recent few years. But energy usage of the system and its efficiency has not been compared with the regular system. So, the potential of using IoT based home automation and remote controlling system has not been uncovered fully. In this paper, an analysis of energy usage comparison between proposed system and regular system has been conducted. It has been shown that, using the proposed system can save almost one-fourth of energy. As home appliances can be controlled remotely and automatically, the system can also give us notification if something goes wrong in our home, even we are from home. Monitoring the usage of the devices, a smarter algorithm can be derived in the future using AI technology.

\section{LITERATURE REVIEW}

IoT based home automation and remote controlling system is not a new technology. Many project and research have been conducted in this sector.

For example, a recent IoT-Cloud based smart home automation system using a web platform to control home appliances was reported [1]. In this system, a homeowner can change the appliances' status using HTTP requests. The important feature of the IoT-Cloud approach is to store the home appliances' status and perform more data analytics. An end-to-end text-based remote-control system for home appliances using a secure mobile applicant was reported in [2]. Based on ZigBee and PLC, an energy management system was reported in [3]. The system monitors and controls lights, the status of appliances, and energy consumption via the Internet based on text commands [4]. An IoT-Based DualMode Smart Home Automation System that uses a touchscreen interface mode and Natural Language Processing (NLP) mode was proposed [5]. K. GB, D. Kumar, K. Pai, Manikandan J proposed a system called design of a phonemebased voice-controlled home automation system where authors researched on different type of voice signals and by using those voice signals, they proposed a home automation system [6]. T. Chakraborty and S. K. Datta presented a system called home automation using edge computing internet of things where they presented edge computing concept in the home automation system [7]. Dr. V. Chayapathy; Dr. Anitha G S; Sharath B presented a paper on IoT based home automation system by using personal assistant [8]. M. AlKuwari with his co-author proposed a system on smart home automation using IoT based Sensing and Monitoring Platform where the authors presented a very basic concept of how a home automation can be done using IoT [9]. Another article offers an analysis of the state of the art of the Internet of Things applied to the management of buildings, highlighting the functions that can be monitored and controlled and the benefits that can be achieved in terms of comfort and energy savings in the various categories of equipment (mechanical, electrical, plumbing, lighting, etc.)[10]. In a work, a home model is analyzed to demonstrate an energy efficient IoT based smart home. Several Multiphysics simulations were carried out focusing on the kitchen of the home model [11]. And many other researches have done different works on this home automation system. Also, many other researchers are still working on this vast field.

\section{SYSTEM ARCHITECTURE}

According to Figure 1. the system consists of a nodeMCU microcontroller connected with a cloud server. Sensors are connected with the microcontroller for automatic operation. A relay module is connected to the nodeMCU for high voltage switching system. The devices are connected with the relay 
module. A smartphone is used to control the system remotely using Internet. The smartphone communicates with the cloud server and the cloud server sends request to the microcontroller.

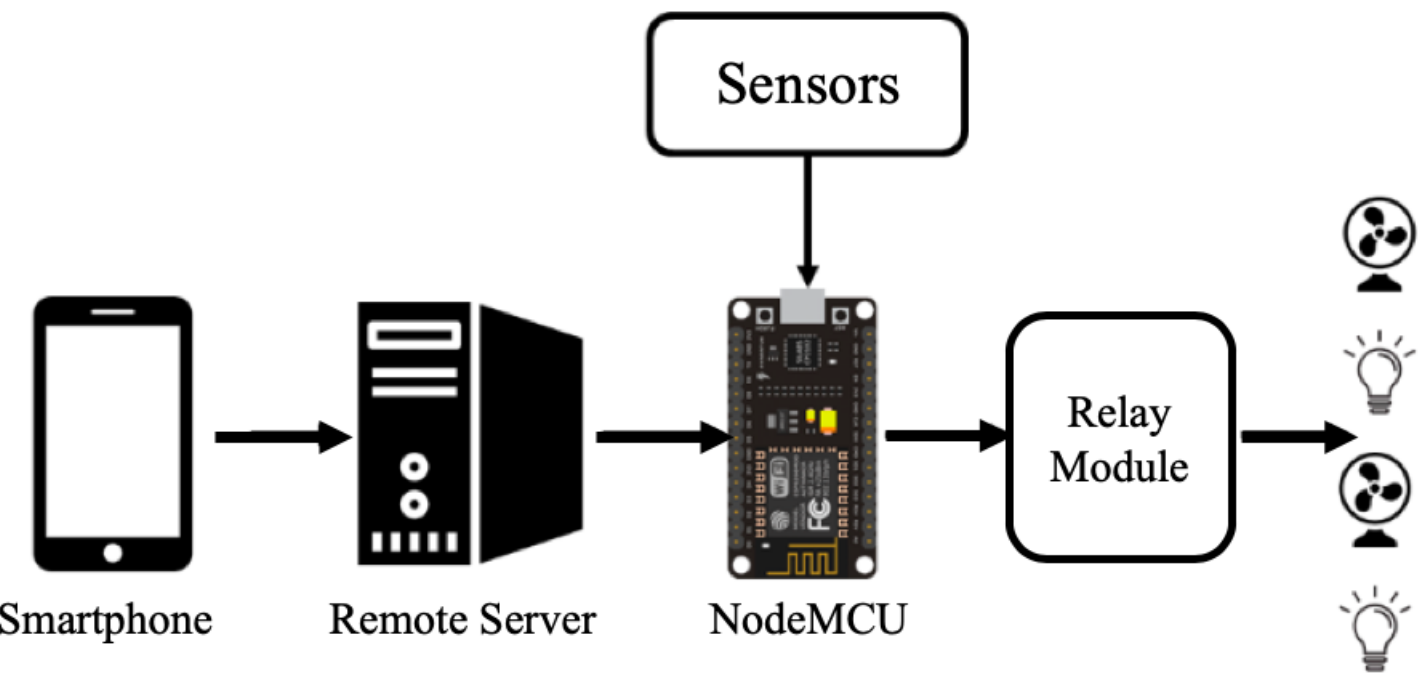

Fig1: Architecture Model of the Proposed System

\section{SYSTEM DESIGN}

The system's main part is nodeMCU and all the other components are connected with it except the mobile app. Figure 2 explains the hardware setup of nodeMCU with other components.

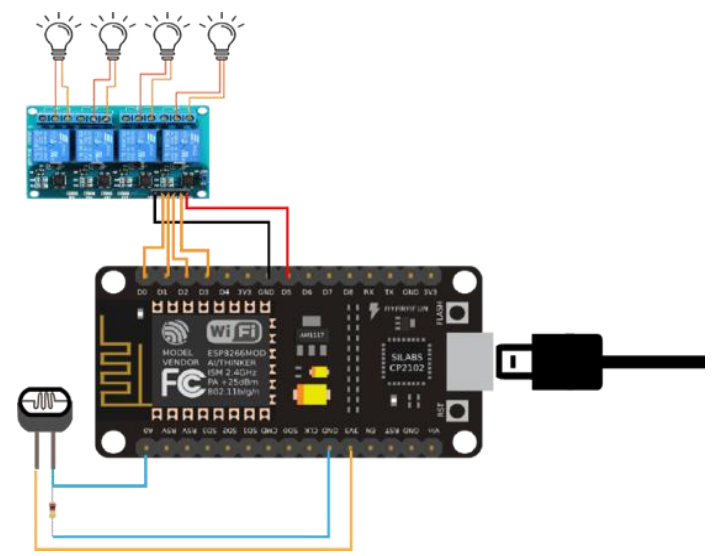

Fig 2: Circuit Diagram of the Proposed System

\section{A. NodeMCU:}

NodeMCU is a low-cost open source IoT platform. It initially included firmware which runs on the ESP8266 Wi-Fi SoC from Espressif Systems, and hardware which was based on the ESP-12 module. Later, support for the ESP32 32-bit MCU was added.

\section{B. Relay Module:}

A relay is basically a switch which is operated by an electromagnet. The electromagnet requires a small voltage to get activated which we will give from the Arduino and once it is activated, it will pull the contact to make the high voltage circuit.

\section{CD74HC4067 16-Channel Analog Digital Multiplexer:}

This is a breakout board for the very handy 16-Channel Analog/Digital Multiplexer/Demultiplexer CD74HC4067. This chip is like a rotary switch - it internally routes the common pin to one of 16 channel pins. It works with both digital and analog signals (the voltage can't be higher than VCC), and the connections function in either direction.
D. Temperature Sensor:

A temperature sensor is a device, usually an RTD (resistance temperature detector) or a thermocouple, that collects the data about temperature from a particular source and converts the data into understandable form for a device or an observer.

\section{E. Photoresistor:}

A photoresistor is an active component that decreases resistance with respect to receiving luminosity on the component's sensitive surface. The resistance of a photoresistor decreases with increase in incident light intensity; in other words, it exhibits photoconductivity.

\section{F. PIR motion Sensor:}

A passive infrared sensor is an electronic sensor that measures infrared light radiating from objects in its field of view. They are most often used in PIR-based motion detectors. PIR sensors are commonly used in security alarms and automatic lighting applications.

\section{G. $\quad$ Cloud Server (Blynk Server):}

Blynk was designed for the Internet of Things. It can control hardware remotely, it can display sensor data, it can store data, visualize it and do many other cool things. It is responsible for all the communications between the smartphone and hardware. You can use our Blynk Cloud or run your private Blynk server locally. It's open-source, could easily handle thousands of devices and can even be launched on a Raspberry Pi.

H. Mobile App (Blynk App):

It allows us to create amazing interfaces for your projects using various widgets we provide. We can control the nodeMCU with the help of this amazing app that can be customized as we need.

\section{SYSTEM MODES}

The system runs in two modes. Automatic and manual. Automatic mode is when we choose to control the devices according to our own will. Manual mode is when we choose to run the system according to the sensor values. The user chooses either automatic mode or manual mode from the mobile app. 


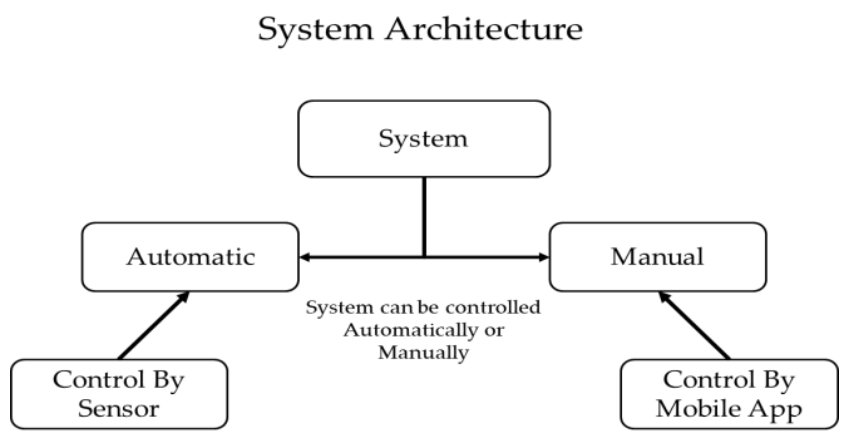

Fig 3: Two different system modes

\section{SIMULATION OF ENERGY USAGE OF TWO SYSTEMS}

A student hall of Chittagong University 'Shaheed Abdur Rab Hall' has been simulated. The hall has 8 one seated rooms, 80 two seated rooms, 10 three seated room and 75 four seated room. Total seat is 498 and each seat has one table/desk lamp, one energy light and one ceiling fan allocated. The power of the electric devices: 30-watt light, 75-watt ceiling fan, 15-watt table lamp. For easy calculation, a two seated room has been taken for simulation. The scenario is of the summer season.

\subsection{Scenario of Regular System:}

A regular system has been observed 24 hours to note when the devices run for how much time. The room has one ceiling fan, two energy light and two table lamps. As the room is a student hostel, there are no other electric device except mobile phone and laptop that have not been considered in the calculation as these types of devices are not included in the proposed system these devices are already smart enough to save energy. The result of observation has been shown in Table 1. The values have been rounded to integer for easier calculation. But the observation has been made in the perspective of a standard Bangladeshi student habit of a University student.

Table 1. Observation of Regular System

\begin{tabular}{|c|c|c|c|c|c|c|c|}
\hline Time slot & $\begin{array}{c}\text { Time } \\
\text { (hour) }\end{array}$ & $\begin{array}{c}\text { Ceiling } \\
\text { Fan }\end{array}$ & $\begin{array}{c}\text { Light } \\
\mathbf{1}\end{array}$ & $\begin{array}{c}\text { Light } \\
\mathbf{2}\end{array}$ & $\begin{array}{c}\text { Table } \\
\text { Lamp } \\
\mathbf{1}\end{array}$ & $\begin{array}{c}\text { Table } \\
\text { lamp } \\
\mathbf{2}\end{array}$ & $\begin{array}{c}\text { Total } \\
\text { energy } \\
\mathbf{c o s t} \\
\mathbf{k W h})\end{array}$ \\
\hline $\begin{array}{c}\text { 12:00 am } \\
-2: 00 \mathrm{am}\end{array}$ & 2 & On & Off & Off & On & On & 0.21 \\
\hline $\begin{array}{c}\text { 2:00 am - } \\
7: 00 \mathrm{am}\end{array}$ & 5 & On & Off & Off & Off & Off & 0.375 \\
\hline $\begin{array}{c}\text { 7:00 am - } \\
9: 00 \mathrm{am}\end{array}$ & 2 & Off & On & On & Off & Off & 0.12 \\
\hline $\begin{array}{c}\text { 9:00 am - } \\
1: 00 \mathrm{pm}\end{array}$ & 4 & Off & Off & Off & Off & Off & 0 \\
\hline $\begin{array}{c}1: 00 \mathrm{pm}- \\
2: 00 \mathrm{pm}\end{array}$ & 1 & On & Off & Off & Off & Off & 0.075 \\
\hline $\begin{array}{c}\text { 2:00 pm - } \\
4: 00 \mathrm{pm}\end{array}$ & 2 & Off & Off & Off & Off & Off & 0 \\
\hline $\begin{array}{c}\text { 4:00 pm - } \\
6: 00 \mathrm{pm}\end{array}$ & 2 & On & Off & Off & Off & Off & 0.15 \\
\hline
\end{tabular}

\begin{tabular}{|c|c|c|c|c|c|c|c|}
\hline $\begin{array}{c}\text { 6:00 pm - } \\
7: 00 \mathrm{pm}\end{array}$ & 1 & On & On & Off & Off & Off & 0.105 \\
\hline $\begin{array}{c}7: 00 \mathrm{pm}- \\
12: 00 \mathrm{am}\end{array}$ & 5 & On & On & On & Off & Off & 0.675 \\
\hline Total & 24 & 16 & 8 & 7 & 2 & 2 & 1.71 \\
\hline
\end{tabular}

\subsection{Scenario of Proposed System:}

After observing the regular system, the proposed system has been observed for another 24 hours in the same room with the same number of electric devices as in the regular system observation. The result of the observation of proposed system has been noted in the Table 2 .

Table 2. Simulation table of proposed system

\begin{tabular}{|c|c|c|c|c|c|c|c|}
\hline Time slot & $\begin{array}{c}\text { Time } \\
\text { (hours })\end{array}$ & $\begin{array}{c}\text { Ceiling } \\
\text { fan }\end{array}$ & $\begin{array}{c}\text { Light } \\
\mathbf{1}\end{array}$ & $\begin{array}{c}\text { Light } \\
\mathbf{2}\end{array}$ & $\begin{array}{c}\text { Table } \\
\text { lamp } \\
\mathbf{1}\end{array}$ & $\begin{array}{c}\text { Table } \\
\text { lamp } \\
\mathbf{2}\end{array}$ & $\begin{array}{c}\text { Total } \\
\text { energy } \\
\mathbf{( k W h})\end{array}$ \\
\hline $\begin{array}{c}12: 00 \mathrm{am} \\
-2: 00 \mathrm{am}\end{array}$ & 2 & On & Off & Off & On & On & 0.21 \\
\hline $\begin{array}{c}2: 00 \mathrm{am}- \\
6: 00 \mathrm{am}\end{array}$ & 4 & On & Off & Off & Off & Off & 0.3 \\
\hline $\begin{array}{c}\text { 6:00 am - } \\
8: 00 \mathrm{am}\end{array}$ & 2 & Off & On & Off & Off & Off & 0.06 \\
\hline $\begin{array}{c}8: 00 \mathrm{am}- \\
1: 00 \mathrm{pm}\end{array}$ & 5 & Off & Off & Off & Off & Off & 0 \\
\hline $\begin{array}{c}1: 00 \mathrm{pm}- \\
2: 00 \mathrm{pm}\end{array}$ & 1 & On & Off & Off & Off & Off & 0.075 \\
\hline $\begin{array}{c}2: 00 \mathrm{pm}- \\
4: 00 \mathrm{pm}\end{array}$ & 2 & Off & Off & Off & Off & Off & 0 \\
\hline $\begin{array}{c}4: 00 \mathrm{pm}- \\
6: 00 \mathrm{pm}\end{array}$ & 2 & On & Off & Off & Off & Off & 0.15 \\
\hline $\begin{array}{c}6: 00 \mathrm{pm}- \\
7: 00 \mathrm{pm}\end{array}$ & 1 & On & On & Off & Off & Off & 0.105 \\
\hline $\begin{array}{c}7: 00 \mathrm{pm}- \\
12: 00 \mathrm{am}\end{array}$ & 5 & On & On & On & Off & Off & 0.675 \\
\hline $\begin{array}{c}\text { Total } \\
\text { time }\end{array}$ & 24 & 15 & 8 & 5 & 2 & 2 & 1.575 \\
\hline
\end{tabular}

\section{ENERGY USAGE}

A simulation has been conducted for 24 hours in a two seated room of Shaheed Abdur Rab Hall of Chittagong University. Firstly, the run time of all the electric devices have been noted in regular system. Then, the same calculation has been done using the proposed system. Then the energy usage is calculated by the formula $w=p t$ where $w, p$ and $t$ denotes energy usage (in $\mathrm{kWh}$ ), power (in kilo watt) of the electric devices and time (in hour) respectively. The energy usage of regular system and proposed system has been shown in Figure 4. 


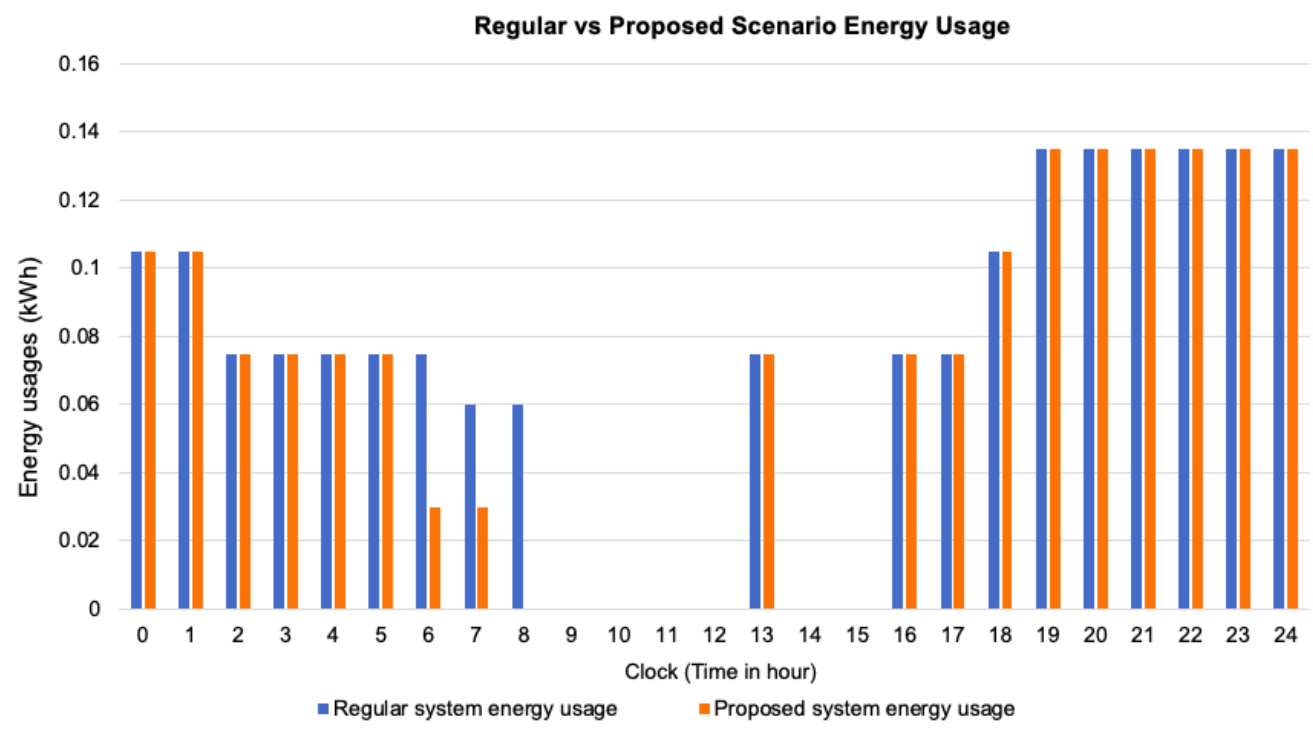

Fig 4: Energy Usage Comparison between two scenarios

\section{RESULTS AND DISCUSSIONS}

The system can save up to $24 \%$ of energy and thus reduce the energy cost. The calculations been performed by simulating 100 living rooms each one having 2 lights, 2 fans and 2 table or desk lamps. Figure 5, Figure 6 and Figure 7 represents us the energy and cost saving result. According to Figure 6. the cost of our proposed system for the first 06 months of first year is slightly higher than our regular system due to initial setup and installment cost. However, the next 06 months the proposed system saves the initial excess energy cost. In the long run, the overall cumulative save for the costing of energy in Bangladesh using our proposed scenario design will be USD 2000000 (for 05 years).

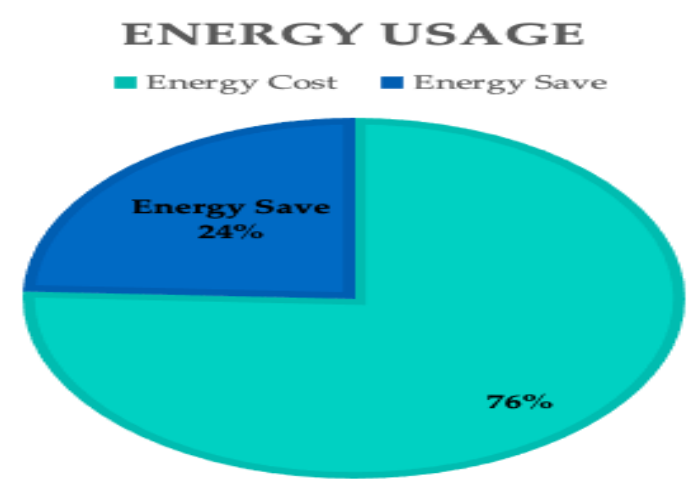

Fig 5: Energy Saving Results Showing in Pie Chart

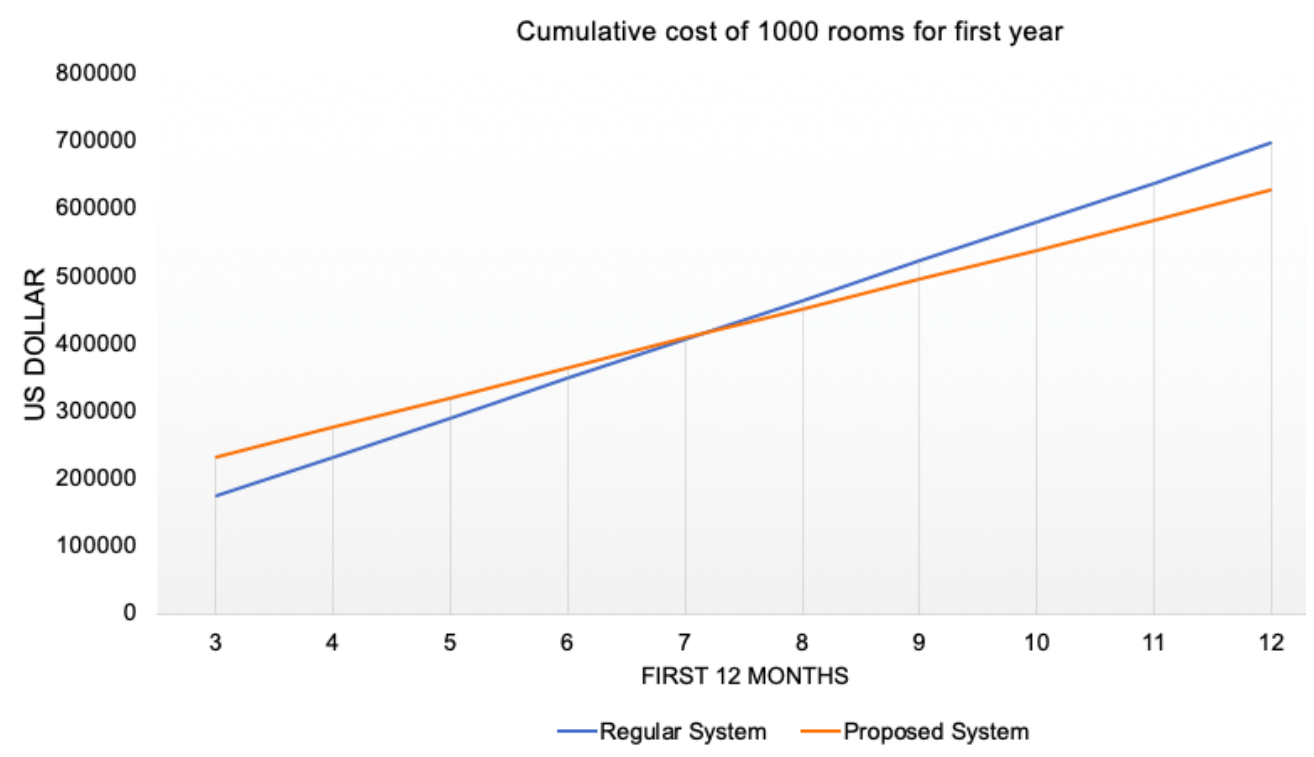

Fig 6: First Year Energy Cost Comparison of Regular and Proposed Scenario System 


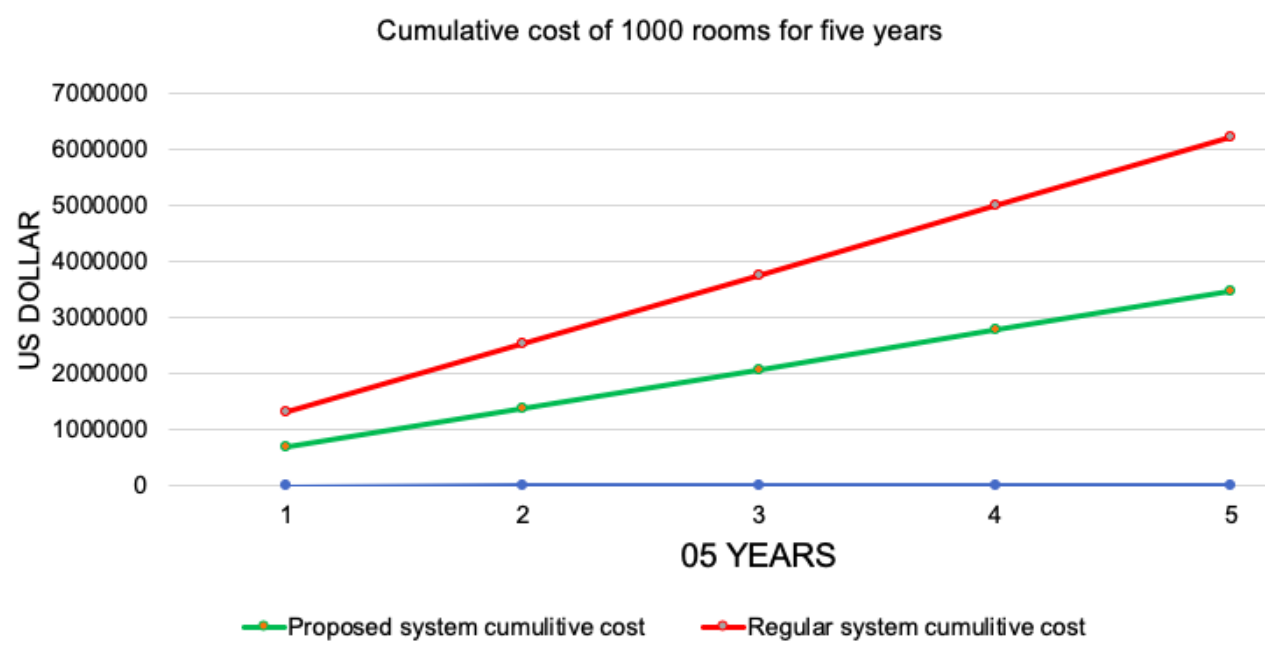

Fig 7: Cumulative Energy Cost Comparison for 5 years

\section{CONCLUSION AND FUTURE PLAN}

We have proposed an IoT based student hall automation system for an well known public university in Bangladesh that can make life easier and save energy. This will definitely help the developed country to save more energy and thus reduce energy cost. Moreover, the disabled student or people also can control the electric devices easily and even we can get alarm when something goes wrong. Connecting more devices of different types and making the system smarter using Artificial Intelligence technology will be our future work.

\section{ACKNOWLEDGEMENTS}

Firstly, we are very much thankful to all the faculty members of Computer Science and Engineering Department, University of Chittagong. Again, we are grateful to the authorities of 'Shaheed Abdur Rab Hall' and University of Chittagong for providing information about the hall and support us every time.

\section{REFERENCES}

[1] Iqbal, A., Ullahb, F., Anwarb, H., Kwaka, K. Sup, Imranc, M., Jamald, W., Rahman, A., Eason, G., Noble, B., and Sneddon, I. N. 2018. Interoperable Internet-ofThings platform for smart home system using Web-ofObjects and cloud. Sustainable Cities and Society, Vol. 38, pp. 636-646.

[2] Tanaka, H., Suzuki, H., Watanabe, A., and Naito, K. 2018. Evaluation of a Secure End-to-End RemoteControl System for Smart Home Appliances. IEEE International Conference on Consumer Electronics (ICCE), pp. 1-2.

[3] Eason, G.1955. On certain integrals of Lipschitz-Hankel type involving products of Bessel functions. Phil. Trans. Roy. Soc. London, vol. A247, pp. 529- 551.
[4] Han, J., Choi, C., Park, Wan-ki., Lee, I., and Kim, SangHa. 2014. Smart Home Energy Management System Including Renewable Energy Based on ZigBee and PLC. IEEE Trans. on Consumer Electronics, Vol. 60, No. 2, pp. $198-202$.

[5] Hamdan, O., Shanableh, H., Zaki, I., Al-Ali, A.R., and Shanableh, T. 2019. IoT-Based Interactive Dual Mode Smart Home Automation. IEEE International Conference on Consumer Electronics (ICCE), Las Vegas, NV, USA, 2019, pp. 1-2.

[6] Karan, G.B., Kumar, D., Pai, K. and Manikandan, J. 2017. Design of a phoneme-based voice-controlled home automation system. IEEE International Conference on Consumer Electronics-Asia (ICCE-Asia), Bangalore, 2017, pp. 31-35.

[7] Chakraborty, T. and Datta, S.K. 2017. Home automation using edge computing and Internet of Things. IEEE International Symposium on Consumer Electronics (ISCE), Kuala Lumpur, 2017, pp. 47-49.

[8] Chayapathy, V., Anitha, G., and Sharath, B.N. (2017) IOT based home automation by using personal assistant. 2017 International Conference On Smart Technologies For Smart Nation (SmartTechCon), 385389.

[9] Al-Kuwari, M., Ramadan, A., Ismael, Y., Al-Sughair, L., Gastli, A., and Benammar, M. 2018. Smart-home automation using IoT-based sensing and monitoring platform. IEEE 12th International Conference on Compatibility, Power Electronics and Power Engineering (CPE-POWERENG 2018), Doha, 2018, pp. 1-6.

[10] Salman, L. and et al. 2016. Energy efficient IoT-based smart home. IEEE 3rd World Forum on Internet of Things (WF-IoT), Reston, VA, 2016, pp. 526-529. 